\section{Mekong dam: invest in public health}

Construction of the Xayaburi dam on the Mekong River in Laos could have serious implications for public health as well as for fishing (Nature 478, 305-307; 2011).

The river and its basin are the natural habitat of the freshwater snail Neotricula aperta. This is the only known intermediate host of the trematode parasite Schistosoma mekongi, a flatworm that causes human schistosomiasis (bilharzia) through contact with infected water.

Newly created upstream water reservoirs, as well as altered river currents and sedimentation, markedly affect the relative distribution of snails carrying different Schistosoma species. When the Aswan High Dam was built in Egypt in 1970, it caused a shift in the relative frequency of schistosomiasis from the urinary (S. haematobium) to the hepatosplenic type (S. mansoni), which is more severe

(M. F. Abdel-Wahab et al. Lancet 314, 242-244; 1979).

Construction of the Three Gorges Dam across the Yangtze River in China is also expected to extend the snail's normal habitat substantially, increasing the likelihood of disease in domestic livestock and humans

(D. P. McManus et al. Clin.

Microbiol. Rev. 23, 442-466; 2010).

The only cost-effective drug currently available to treat infection is the schistosomicide praziquantel. However, parasite resistance to this drug is emerging as a result of mass administration programmes and high rates of reinfection in endemic areas (S. D. Melman et al. PLoS Negl. Trop. Dis. 3, e504; 2009).

A plea on behalf of poor people living along the Mekong's banks is unlikely to affect the construction of economically important projects such as the Xayaburi dam. Instead, some of the dam's revenues should be invested in the development of new antischistosomal drugs and vaccines.

Antoni R. Blaazer Bilharzia Foundation, Wormerveer, the Netherlands.ton.blaazer@ bilharziafoundation.org

\section{Mekong dam: assess health risks}

Huge hydroelectric projects (see, for example, Nature 478, 305-307; 2011) can have a negative impact on public health, particularly in tropical areas. Public and private power companies should be obliged to assess this risk and incorporate it into their development policies.

It was pointed out ten years ago that the World Commission on Dams, created in 1998 by the World Bank and the International Union for Conservation of Nature, had fallen short in analysing health issues (A. C. Sleigh and S. Jackson Lancet 357, 570-571; 2001). This oversight has still not been rectified: the Strategic Environmental Assessment of Hydropower on the Mekong Mainstream, for example, did not include public-health risks or the likely consequences in its report.

The failure to develop strategies to mitigate emerging or re-emerging infectious diseases in this context probably stems from ignorance and financial considerations. Reliable analysis of environmental and societal health risks is essential for their prevention and control, which depend on evidencebased guidance for health policy and planning. It is also crucial to optimize integrated surveillance systems to allow timely responses to public-health threats.

The 1,070-megawatt Nam Theun 2 hydropower station in central Laos has shown that longterm surveillance and monitoring of vector-borne diseases is achievable at an acceptable cost. Gilles Guerrier Paris, France. guerriergilles@gmail.com

\section{Space telescope: debt problems go deeper}

You report concern among some US planetary scientists that the funding for the James Webb Space Telescope (JWST) is preventing NASA from providing a rocket for the 2016 ExoMars launch (see go.nature.com/zimumq and go.nature.com/emqasy). But this is not the root of the problem.

The real issue is the dismal five-year budget projection for NASA's Solar System exploration in US President Barack Obama's budget proposal from February 2011 - a projection driven by debt-reduction pressures across all federal agencies.

A look at more recent versions of the 2012 budget - one from the House of Representatives, which provides no money for the JWST, and the other from the Senate, which gives enough this year to support a launch in 2018 - reveals that identical amounts are provided for Solar System exploration. It is therefore clear that cancellation of the JWST will lead to debt reduction and not to a transfer of funds to planetary missions, a point made explicitly in the House budget text.

The JWST will peer back in time to the beginnings of the cosmos while measuring the composition of atmospheres of super-earths around nearby stars. The challenge for space scientists is to make the case that such exploration is worthwhile, even in difficult economic times. If we attack one another's programmes, we shall see funds for many of our hard-fought missions swept away in the name of deficit reduction - and we shall all lose out.

Jonathan I. Lunine Cornell University, Ithaca, New York, USA.jlunine@astro.cornell.edu

\section{Space telescope: focus on priorities}

The concerns and frustration of the planetary community over the uncertainty of the 2016 ExoMars mission are understandable (see go.nature. com/zimumq). Several budgetary factors are to blame, and these precede and are unrelated to the recently increased costs of launching the James Webb Space Telescope.

The US President's 2012 budget proposal for NASA's Planetary Science Division, released in February 2011, dropped from the previous year's figure by roughly US $\$ 1$ billion over the next five years.

In addition, the cost of the Mars Science Laboratory, initially estimated at $\$ 650$ million in 2003 (at a time when all major mission costs were underestimates), has risen to around $\$ 2.5$ billion.

The cost of the missions in NASA's Science Mission Directorate budget for 2008 was also found to be understated by billions of dollars.

The scientific community needs to support the decadal priorities of each of the science divisions at NASA and avoid firing inwards, which will threaten funding for science overall.

Garth D. Illingworth University of California Santa Cruz, California, USA. gdi@ucolick.org

\section{Sea-ice loss sparks oil drilling boom}

An irony that should give us all reason to pause is that the unprecedented, climate-induced loss of Arctic sea ice (Nature 478, 171; 2011) has triggered an explosion of oil exploration off Greenland and in the Kara, Barents and Chukchi seas. James B. McClintock University of Alabama at Birmingham, Alabama, USA.

mcclinto@uab.edu

CONTRIBUTIONS

See author guidelines at http://go.nature.com/ cmchno. 